\title{
PROPOSTA DE IMPLEMENTAÇÃO TECNOLÓGICA COMO OPORTUNIDADE DE ALCANÇAR UM NOVO NICHO DE MERCADO PARA ACADEMIAS: ESTUDO DE CASO NA EMPRESA CROSS NUTRITION BOX MANAUS
}

\section{ARTIGO ORIGINAL}

PEREIRA, Trícia Calazans ', SANTOS, Alexesander Soares dos 2, CONCEIÇÃO JÚNIOR, Evandro Ribeiro ${ }^{3}$, ROBERTO, José Carlos Alves ${ }^{4}$

PEREIRA, Trícia Calazans. Et al. Proposta de implementação tecnológica como oportunidade de alcançar um novo nicho de mercado para academias: estudo de caso na empresa Cross Nutrition Box Manaus. Revista Científica Multidisciplinar Núcleo do Conhecimento. Ano 06, Ed. 05, Vol. 04, pp. 149-168. Maio de 2021. ISSN: 2448-0959, Link de acesso: https://www.nucleodoconhecimento.com.br/administracao/implementacaotecnologica, DOI: 10.32749/nucleodoconhecimento.com.br/administracao/implementacao-tecnologica

\section{RESUMO}

Este artigo tem a finalidade de propor a implementação de ferramentas do marketing e softwares para captação e fidelização de clientes na academia Cross Box Nutrition Manaus. Na primeira etapa do diagnóstico organizacional, identificou-se que a área

${ }^{1}$ Graduanda do curso de Administração.

2 Graduando do curso de Administração.

${ }^{3}$ Graduando do curso de Administração.

${ }^{4}$ Mestrado profissional em Engenharia de produção. Especialização em Gestão em Logística empresarial. Graduação em Administração com Ênfase em Marketing.

$\mathrm{RC}: 84713$

Disponível em: https://www.nucleodoconhecimento.com.br/administracao/implementacaotecnologica 
marketing é a mais crítica pela ausência de pesquisa de satisfação com os clientes, estratégia de divulgação da marca e serviços inovadores. A pesquisa teve como objetivo: Identificar quais metodologias podem ser aplicadas, para captar e fidelizar clientes por meio da implementação de serviços diferenciados no mundo fitness, nos objetivos específicos: Identificar e analisar plataformas digitais; serviços inovadores; aplicação de ferramentas, e como o mercado fitness online é atrativo para a organização. A metodologia aplicada na pesquisa, quanto aos fins, foi exploratória e descritiva, quanto aos meios, foi bibliográfica e de levantamento de dados. A ferramenta da qualidade $5 \mathrm{~W} 2 \mathrm{H}$ foi utilizada para a proposta de implementação nas ações de melhoria indicadas: desenvolver conteúdo para plataforma online de treinos; aquisição e implantação da plataforma; estruturar procedimentos de marketing digital e aplicação do software CRM. Com isso espera-se o acompanhamento das ações de melhoria e responsabilidades de execução, tendo como resultados a satisfação e fidelização dos clientes através de serviços inovadores e ferramentas do marketing.

Palavras-chave: Marketing, plataforma online, fidelizar, serviços, inovação.

\section{INTRODUÇÃO}

Este artigo aborda o estudo de caso elaborado na empresa Cross Nutrition Box Manaus, sendo feito observações internas para analisar uma provável adversidade e assim, em um momento subsequente sugestionar uma proposta viável de solução. Com base na pesquisa realizada na organização, o setor de marketing foi constado como a área mais crítica da empresa, tendo como principais pontos instáveis, a falta de divulgação da marca, a indisponibilidade de um serviço diferenciado e inovador e a ausência da empresa na pesquisa de satisfação do cliente.

O objetivo geral do trabalho é identificar quais metodologias podem ser aplicadas, visando a captação e fidelização de clientes por meio da implementação de serviços diferenciados no mundo fitness, ordenando juntamente com os objetivos específicos, sendo eles: Identificar os serviços diferenciados por meio de plataformas online afim

RC: 84713

Disponível em: https://www.nucleodoconhecimento.com.br/administracao/implementacaotecnologica 
de alcançar e fidelizar clientes, Analisar como pode ser feita a captação e fidelização de clientes por meio de plataformas digital, e como o mercado fitness online é atrativo para a organização, por fim, Propor a aplicação de ferramentas do marketing afim de vincular e satisfazer os clientes através de serviços inovadores oferecidos pela academia.

Posteriormente com o estudo criado através de pesquisas na empresa, será discorrido neste artigo as seguintes soluções para a problemática no departamento de marketing: a implantação de uma plataforma online, sendo possível a venda dos serviços oferecidos virtualmente pela empresa, a necessidade do uso do marketing digital, assim como a utilização das ferramentas CRM e $5 \mathrm{~W} 2 \mathrm{H}$, que são capazes de proporcionar meios para solucionar tal problema nesse setor, visto que 0 planejamento estratégico da empresa Cross Nutrition Box Manaus é promover melhorias na marca e serviços continuamente, com o foco de atrair crescentemente clientes interessados em desfrutar de seus serviços.

Portanto, após as realizações das análises do processo de planejamento estratégico abordaremos neste artigo etapas para adequação da empresa a proposta de solução e estratégia ao qual beneficiará o crescimento da marca no mercado.

\section{FUNDAMENTAÇÃO TEÓRICA}

A fundamentação teórica é uma base para o que será abordado no decorrer da pesquisa, portanto é importante mencionar conceitos que facilitem o entendimento $\mathrm{e}$ compreensão científicas do artigo, pois ela busca estudar e se aprofundar em teses, livros, artigos, documentos, relatórios, com capacidade de interpretar, discutir e de dialogar com os autores, servindo de orientação para a análise e interpretação dos dados coletados para a pesquisa.

RC: 84713

Disponível em: https://www.nucleodoconhecimento.com.br/administracao/implementacao$\underline{\text { tecnologica }}$ 
Conforme Zanella (2013, p.56) aborda: "A elaboração da fundamentação teórica tem como objetivo apresentar os estudos sobre o tema, ou especificamente sobre o problema de pesquisa, realizados por outros autores".

\subsection{CONCEITO DE MARKETING}

Em síntese, o marketing é capaz de fornecer valores para satisfazer as carências do mercado através de produtos ou prestação de serviços que podem vir a interessar os consumidores. Tendo como finalidade, criar valor e conquistar clientes, gerando para ambas as partes relacionamentos lucrativos, pois suprirão a necessidade um do outro.

Segundo Peter e Donnely (2017) o marketing é a centralização de procedimentos que dispõem de objetivos como: criar, comunicar e fornecer valor aos clientes e conduzir a captação e fidelização dos mesmos, afim de beneficiar a organização.

O marketing na empresa visa focar nas pessoas, especificamente na atração de consumidores, com intuito de investir em atendimento de qualidade que possibilite criar laços, afim de torná-los como integrantes da organização. O mesmo propõe a empresa inovar e buscar um diferencial claro, pois seu objetivo é tornar a marca única e ser diferente dos concorrentes, para que tenha sua própria identidade.

\subsection{CAPTAÇÃO DE CLIENTES}

Após entender como é imprescindível o marketing para a empresa, nota-se que alinhado ao conhecimento do segmento que se identifica torna-se mais fácil atingir o público-alvo e seu objetivo organizacional. Por meio das ferramentas do marketing digital, como as mídias sociais a captação e criação de vínculo acontece de forma mais rápida e precisa, facilitando o relacionamento cliente/organização.

Segundo Raiol (2020) depois que o público-alvo é delimitado, é necessário trabalhar os serviços e produtos destacando os diferenciais dentre os concorrentes de mercado. RC: 84713

Disponível em: https://www.nucleodoconhecimento.com.br/administracao/implementacaotecnologica 
Com isto, a organização consegue entender e suprir as necessidades dos clientes em potencial. Marangoni $(2015$, p.52) afirma que ".. a o oferta que proporcionar maior valor para o cliente refletirá benefícios por ele percebidos, podendo estar relacionado a qualidade, serviço e preço". Por intermédio de ferramentas do marketing como marketing digital, a captação do público-alvo pode ter resultados satisfatórios.

\subsection{MARKETING DIGITAL}

Sabendo que o mundo comercial está incessantemente em mudança, surgiu por parte das organizações a busca de alternativas para conquistar a atenção dos clientes, com desejo de mantê-los a longo prazo junto à empresa. Sendo que, as técnicas no meio online criadas pelo marketing digital, também são de suma relevância, pois colaboram com a empresa adquirindo um espaço significante para sua marca.

Segundo Kotler, Kartajaya e Setiawan (2017, p.79): "O marketing digital não pretende substituir o marketing tradicional. Pelo contrário, ambos devem coexistir, com papéis permutáveis, ao longo do caminho do consumidor".

O marketing digital surge exatamente como a principal solução para essa função, pois além de proporcionar maior visibilidade a empresa, dispõe do objetivo de atrair pessoas interessadas, afim de vivenciar uma experiência única através dos serviços e produtos prestados. Sendo responsabilidade da empresa atrair consumidores para se manter competitiva.

\subsection{PLATAFORMA DIGITAL PARA TREINOS}

Em meio a crises e constantes mudanças em um mundo globalizado surgem contratempos e oportunidades, que se bem gerenciados podem ser favoráveis para o empreendimento. Cabe ao gestor moderno expandir sua visão holística para reinventar o seu negócio quando necessário, afim dos danos serem inferiores à vantagem competitiva e diferencial que pode obter com as mudanças.

RC: 84713

Disponível em: https://www.nucleodoconhecimento.com.br/administracao/implementacaotecnologica 
Para Marangoni (2015) a facilidade que a internet proporciona à comunicação entre empresa e cliente, se tornou um instrumento poderoso para todo tipo de transferências de dados e perpassar informações promovendo o relacionamento com o cliente.

Com isto surge a oportunidade para expansão de negócio no mercado virtual, a criação de uma plataforma digital para treinos. Facilitando a transmissão de treinos funcionais para alunos, sem limitar-se ao ambiente presencial e territorial. Com opções de aulas ao vivo e gravadas, possibilitando que sejam assistidas a qualquer horário e local. Proporcionando ao cliente/aluno a flexibilidade para execução das atividades, conforme sua necessidade.

Segundo Bertão (2020) sobre treinos online: "Além de gerar receita extra aos parceiros, essa modalidade também é uma oportunidade de escalar o negócio, já que não há limitação de espaço físico para acomodar pessoas - cada uma faz a aula da sua casa, mas ao mesmo tempo, e seguindo um professor". O serviço e/ou produto novo ofertado despertará uma curiosidade no público-alvo da organização.

\subsection{AUTOMAÇÃO DE MARKETING}

Automação de marketing é a aplicação de softwares e outras tecnologias afim de otimizar e automatizar as ações do dia a dia em uma organização, como aumentar os resultados ou processos de vendas, permitindo que tenha um retorno maior em novos clientes, leads ou somatório de prospects.

Segundo Souto (2020) através da automação a organização consegue elevar sua receita e melhorar o faturamento, além de diminuir a duração do ciclo de venda e o custo da retenção de consumidores.

Por meio dela, possibilita a organização identificar oportunidades de negócio e potenciais consumidores. Permitindo que a organização consiga filtrar no software dados que considerem importantes para determinar suas decisões, propiciando a

RC: 84713

Disponível em: https://www.nucleodoconhecimento.com.br/administracao/implementacaotecnologica 
mesma a construir sua estratégia direcionada a um objetivo específico com maior chance de eficácia.

Empresas que automatizam suas ações veem benefícios como a melhor maneira de usar seu tempo e decisões baseadas em elementos reais, o que facilita e dar maior segurança no dia a dia ao gerenciamento das informações e na tomada de decisões. Para ter um resultado melhor, é necessário a integração com um sistema de gestão de relacionamento com o cliente (CRM) que mantém o lançamento de informações como compras preferidas, data de nascimento entre outros no sistema.

\subsection{INTRODUÇÃO AO CRM E SUAS ESTRATÉGIAS}

Customer Relationship Management (CRM) gestão de relacionamento com o cliente, sendo atualmente uma grande frente do marketing digital envolve a automação de processos de marketing para o melhor relacionamento com o cliente. Um sistema que reúne e integra dados valiosos para a tomada de decisões precisas.

"O CRM é mais do que uma simples tecnologia, pois se trata de uma ferramenta estratégica que visa maiores lucros por meio do melhor gerenciamento dos relacionamentos com os clientes". (MARANGONI, 2015, p.139).

O foco principal do CRM é automatizar qualquer tipo de contato com o consumidor, sendo uma plataforma com o intuito de coletar dados dos seus clientes e leads, organizar esses dados e permitir o cruzamento dessas informações com as suas ações praticadas na plataforma, assim é possível saber o que os clientes buscam e supri-los através das suas necessidades e até mesmo novas aquisições.

Para Baptista (2016) o software possibilita que todos os envolvidos na organização tenham acesso as informações que proporcionam um relacionamento direto com o cliente, informações essas não limitadas somente as centrais de atendimento.

RC: 84713

Disponível em: https://www.nucleodoconhecimento.com.br/administracao/implementacaotecnologica 
Para a companhia o CRM vai viabilizar a forma de obter dados cadastrais dos consumidores, que armazene todas as ações de compras e disponibilize informações referente aos gostos e necessidades dos clientes e leads, mantendo dados constantemente atualizados e alcançando novos consumidores. Tendo em consideração vendas futuras, estabelecendo aquisições de produtos e serviços específicos mais procurados na plataforma, o software será o meio fundamental para a precisão da necessidade do público da empresa.

\subsubsection{FIDELIZAÇÃO DE CLIENTES}

Observa-se que o princípio para fidelizar os clientes é saber o que, quando e quanto consomem os produtos ou serviços. Com isso podem alcançar as expectativas e necessidades do público-alvo.

No mercado atual para a empresa se manter presente na mente dos consumidores é imprescindível trabalhar os meios de relacionamento, visando criar um vínculo emocional entre a marca e o cliente. É importante captar novos clientes, porém o custo é maior, já para mantê-los o custo é inferior, mais atrativo e econômico para as organizações.

A satisfação é avaliada através de questões que o cliente obteve ou observou, se a percepção for maior daquilo desejado, o cliente ficará mais satisfeito que o esperado. Mas caso seja menor, o mesmo não corresponde a experiência positivamente. Logo se faz necessário o acompanhamento do contentamento dos clientes com os produtos e serviços oferecidos, para firmar e manter os mesmos através do que lhes são ofertados.

O CRM surgiu para auxiliar a gestão de venda a se envolverem melhor com seus consumidores e a entenderem as especificações do seu grupo-alvo. "O marketing de relacionamento resulta em fortes vínculos econômicos, técnicos e sociais entre as

RC: 84713

Disponível em: https://www.nucleodoconhecimento.com.br/administracao/implementacaotecnologica 
partes. Também reduz os custos de transação e o tempo, pois passam a ser rotineiras." (SILVA, 2015, p.17).

\subsection{FERRAMENTA DA QUALIDADE}

As ferramentas da Qualidade são constantemente usadas como suporte ao desenvolvimento da qualidade e ajuda na análise de determinadas questões para definir a decisão final. Seu grande potencial, está evidenciado quando dispostos para a identificação da origem dos problemas junto a resolução dos mesmos.

Para Rodrigues Leite (2013) os instrumentos da qualidade são métodos destinadas a estimar, descrever e pretender meios para solucionar problemas que possam interferir no desempenho produtivo de empresas.

Essas ferramentas são utilizadas para formação e implementação de soluções, análise de resultados, priorização e identificação de problemas. A aplicação dos instrumentos gerenciais tem um resultado satisfatório pois está ligado à importância da informação, acesso, disponibilidade, registro e colaboração dos funcionários na organização.

Baseando-se no uso de ferramentas gerenciais, proporciona velocidade no processo produtivo através da solução imediata de problemas e confronto de resultados, podendo alterar ou aceitar as soluções empregadas durante o desenvolvimento. Segundo Kuendee (2017) as ferramentas da qualidade tem potencial para serem utilizadas em qualquer fase e tipo de processo produtivo, sendo eficazes em levantamentos de informações e identificações de problemas e soluções.

\section{$2.85 \mathrm{~W} 2 \mathrm{H}$}

Essa ferramenta da qualidade é um complexo de questões que são utilizadas para organizar um plano de ação de maneira imediata e eficiente, tendo como principal

RC: 84713

Disponível em: https://www.nucleodoconhecimento.com.br/administracao/implementacaotecnologica 
finalidade a definição, descrição de tarefas e o acompanhamento ágil e simples. Ela permite, identificar dados essenciais em um projeto.

Conforme Custódio (2015) o 5W2H é o planejamento de uma ação organizada e simples, que conduz a resposta para os problemas, colocando de forma prática, analisando assim os principais componentes a serem tratados.

Para operar com essa ferramenta, deve-se observar primeiramente que ela aplica sete perguntas durante seu processo, sendo elas, 5W: What's: o que deve ser feito?; Why: por que precisa ser feito?; Who: quem deve agir?; Where: onde será realizado?; When: quando deverá ser executado?; e 2H: How; como será guiado?; How Much: quanto custará?. Tendo essas respostas, será possível notar com clareza as mudanças a serem empregadas e planejar de forma estratégica as soluções mais viáveis para atingir o propósito esperado da organização.

Geralmente o $5 \mathrm{~W} 2 \mathrm{H}$ é construído por uma tabela, incluindo cada uma das perguntas citadas em um lugar para que seja possível ter as respostas necessárias. Desse modo, fica claro a verificação do andamento de cada ação, ter o monitoramento do tempo gasto, impedir que recursos sejam desperdiçados e supervisionar o desempenho de cada atividade.

Segundo Veras (2016) a ferramenta $5 \mathrm{~W} 2 \mathrm{H}$ é uma tabela composta de atividades que necessitam ser feitas com clareza pelo colaborador responsável pelo projeto.

\section{MATERIAIS E MÉTODOS}

Tendo em base que a metodologia é o ramo em que se trabalha os métodos e ferramentas da melhor forma, ela pode ser quanto à natureza, meios e fins dependendo assim dos materiais e métodos utilizados na apuração de dados coletados através da pesquisa.

RC: 84713

Disponível em: https://www.nucleodoconhecimento.com.br/administracao/implementacao$\underline{\text { tecnologica }}$ 
Segundo Zanella (2013) o método é o meio, e a forma que visa expandir o conhecimento sobre certo conteúdo, ato ou acontecimento. É uma sequência de procedimentos racionais e técnicos adotados para alcançar o conhecimento.

Em vista disso, este trabalho utilizará diversos meios para analisar as melhores formas e métodos que possibilitem identificar soluções adequadas, para que se encaixem às necessidades e capacidades dos problemas encontrados na empresa Cross Nutrition Box Manaus.

\subsection{PROCEDIMENTOS METODOLÓGICOS}

A decisão dos métodos são representados pelos procedimentos metodológicos, pois é a forma de pesquisa que será utilizada. Sendo que este projeto foi realizado, por meio de apuração e condução de informações e dados. Tendo como finalidade planejar os processos, os dispositivos e as técnicas que possam ajudar na captação e fidelização de clientes.

\subsubsection{QUANTO À NATUREZA}

Segundo Libório e Terra (2015) o responsável pela pesquisa para a utilização das técnicas de análise, terá que ter habilidades sobre o assunto e o entendimento sobre os métodos científicos. Utilizando assim conhecimentos teóricos e práticos para responder as questões formuladas.

No projeto a natureza empregada foi aplicativa, já que os dispositivos, processos e tecnologias planejadas podem ser operadas na empresa. O processo de pesquisa teve uma atuação mista ou quali-quantitativa, pois no primeiro momento foi feito um estudo de dados através de entrevistas e coleta de informações, para assim ter uma análise mais específica mediante observação direta, sendo ela qualitativa.

RC: 84713

Disponível em: https://www.nucleodoconhecimento.com.br/administracao/implementacaotecnologica 


\subsubsection{QUANTO AOS FINS}

Quanto aos fins, a pesquisa é classificada como exploratória para apurações mais explícitas em decorrência dos levantamentos aplicados com o fim de argumentar as questões abordadas pelo artigo, descritiva afim de expor os fatores estabelecidos na pesquisa através de fundamentações teóricas, identificando e esclarecendo os problemas.

Conforme afirmam Carvalho et al (2019) a pesquisa descritiva assume o formato geral de levantamento, está ligada ao encargo de descrever os fatores diante o elemento analisado.

\subsubsection{QUANTO AOS MEIOS}

Quanto aos meios, utilizou-se o procedimento bibliográfico com o intuito de acrescentar conhecimentos científicos de maneira a complementar e aprimorar o artigo, usou-se também o procedimento de levantamento, aplicado na empresa para captação de informações através de questionários, assim facilitando as dúvidas e questões da pesquisa por meio de dados coletados da organização.

Para a autora Vergara (2016) a pesquisa bibliográfica está atrelada a obtenção de dados e informações cientificas, tendo como seus principais meios livros e artigos científicos.

\subsection{CARACTERÍSTICAS DA EMPRESA}

A filial Cross Nutrition Box Manaus é uma academia de treino funcional, no estilo Militar e Cross Training. Localizada em Manaus-AM, na Rua Waldemar Jardim Maués, no bairro Novo Aleixo, CEP 69098-455, onde atua buscando atender seus clientes através de um atendimento diferenciado com seus produtos e serviços. Inaugurada

RC: 84713

Disponível em: https://www.nucleodoconhecimento.com.br/administracao/implementacaotecnologica 
em 29 de junho de 2020, oferecem 2 produtos/serviços: Atividade de Cross Training e Suplementos Nutricionais.

\section{RESULTADOS E DISCUSSÕES}

Com base no Diagnóstico Organizacional realizado na empresa Cross Nutrition Box Manaus, obteve-se um levantamento de informações por meio de visita de campo e entrevistas. Onde após o estudo feito, foi constatado pontos que se sobressaíram dentre as áreas funcionais da organização. Conforme mostra o Gráfico 01: Medição de desempenho a seguir.

Gráfico 01: Medição de desempenho áreas funcionais

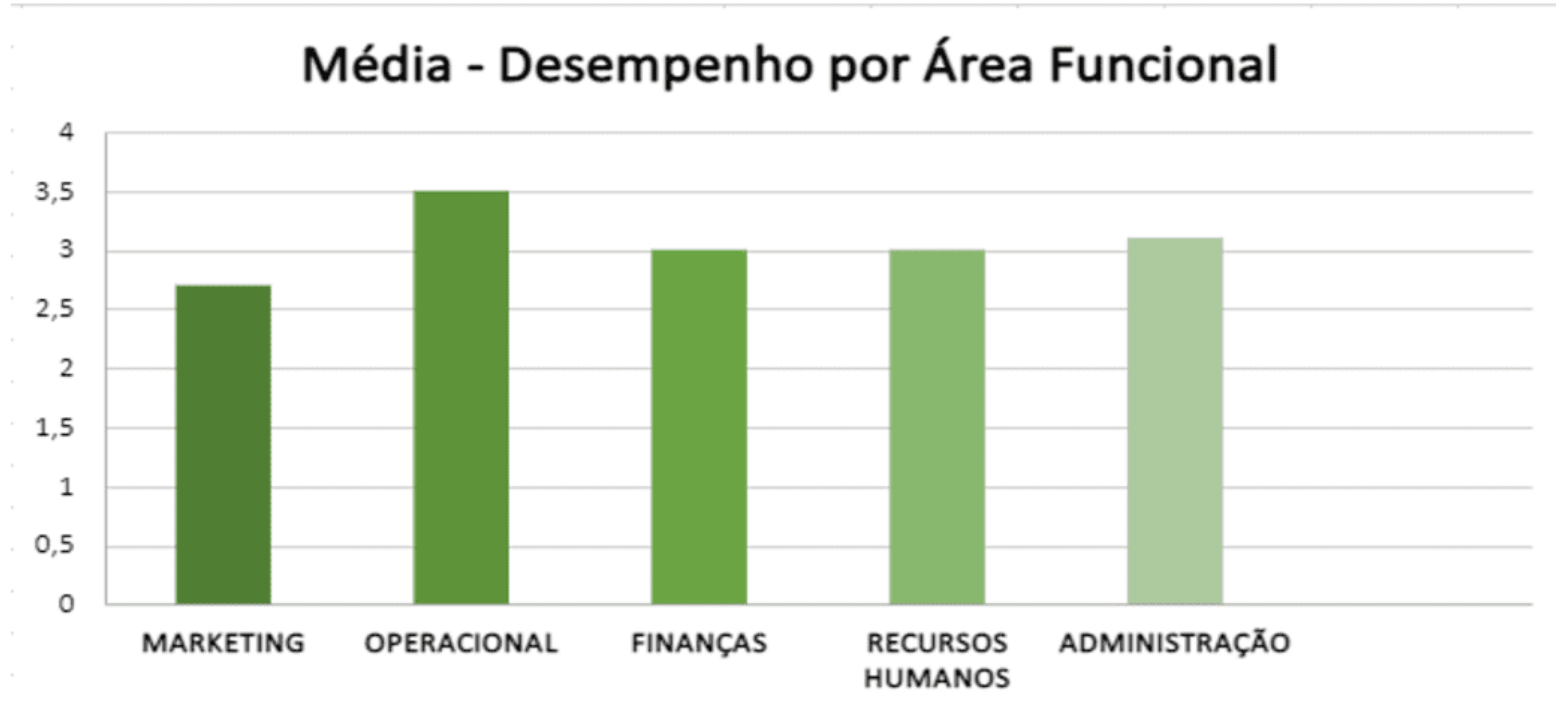

Fonte: Elaborado pelos autores do diagnóstico mediante pesquisa em campo, 2020.

O Gráfico 01 acima foi desenvolvido através de entrevistas e questionários direcionados ao gestor e funcionários da organização, onde foram analisados 10 fatores críticos em cada departamento. O resultado foi obtido por intermédio das pontuações atribuídas com valores entre 5,0 (ponto muito forte) e 1,0 (ponto muito fraco). O total das pontuações em cada setor proporcionou o cálculo da média entre

RC: 84713

Disponível em: https://www.nucleodoconhecimento.com.br/administracao/implementacaotecnologica 
as áreas funcionais, possibilitando a identificação por meio quantitativo da área mais crítica da organização.

Observa-se que a área operacional e administrativa como as de melhor desempenho; finanças e recursos humanos são áreas de médio desempenho. A área funcional Marketing foi classificada como a mais crítica da organização como o gráfico acima pôde apresentar. A seguir no Quadro 01, estão apresentados os fatores críticos analisados na área funcional Marketing.

Quadro 01: Marketing

\begin{tabular}{|c|c|c|c|c|c|c|}
\hline \multirow{2}{*}{\multicolumn{2}{|c|}{$\begin{array}{l}\text { ÁREA FUNCIONAL } \\
\text { MARKETING }\end{array}$}} & \multicolumn{5}{|c|}{ NIVEL OU GRAU DE AVALIAÇÃO } \\
\hline & & \multirow{2}{*}{$\begin{array}{l}\text { Ponto } \\
\text { muito } \\
\text { forte } 5\end{array}$} & \multirow{2}{*}{$\begin{array}{l}\text { Ponto } \\
\text { forte } 4\end{array}$} & \multirow{2}{*}{$\begin{array}{l}\text { Ponto } \\
\text { médio } 3 \\
\text { X }\end{array}$} & \multirow{2}{*}{$\begin{array}{l}\text { Ponto } \\
\text { fraco } 2\end{array}$} & \multirow{2}{*}{$\begin{array}{l}\text { Ponto } \\
\text { muito } \\
\text { fraco } 1\end{array}$} \\
\hline 1 & $\begin{array}{l}\text { Qualidade dos produtos } \\
\text { ou serviços reconhecida } \\
\text { pelo mercado }\end{array}$ & & & & & \\
\hline 2 & $\begin{array}{l}\text { A empresa cultiva } 0 \\
\text { relacionamento com seus } \\
\text { clientes? }\end{array}$ & & & $x$ & & \\
\hline 3 & $\begin{array}{l}\text { Variedade de serviços } \\
\text { Cross training }\end{array}$ & & & $\mathrm{x}$ & & \\
\hline 4 & $\begin{array}{l}\text { A empresa possui preços } \\
\text { competitivos com } \\
\text { mercado fitness? }\end{array}$ & & & $x$ & & \\
\hline 5 & $\begin{array}{l}\text { A localização da empresa } \\
\text { favorece a prospecção } \\
\text { das vendas? }\end{array}$ & & & $\mathrm{x}$ & & \\
\hline
\end{tabular}

RC: 84713

Disponível em: https://www.nucleodoconhecimento.com.br/administracao/implementacaotecnologica 


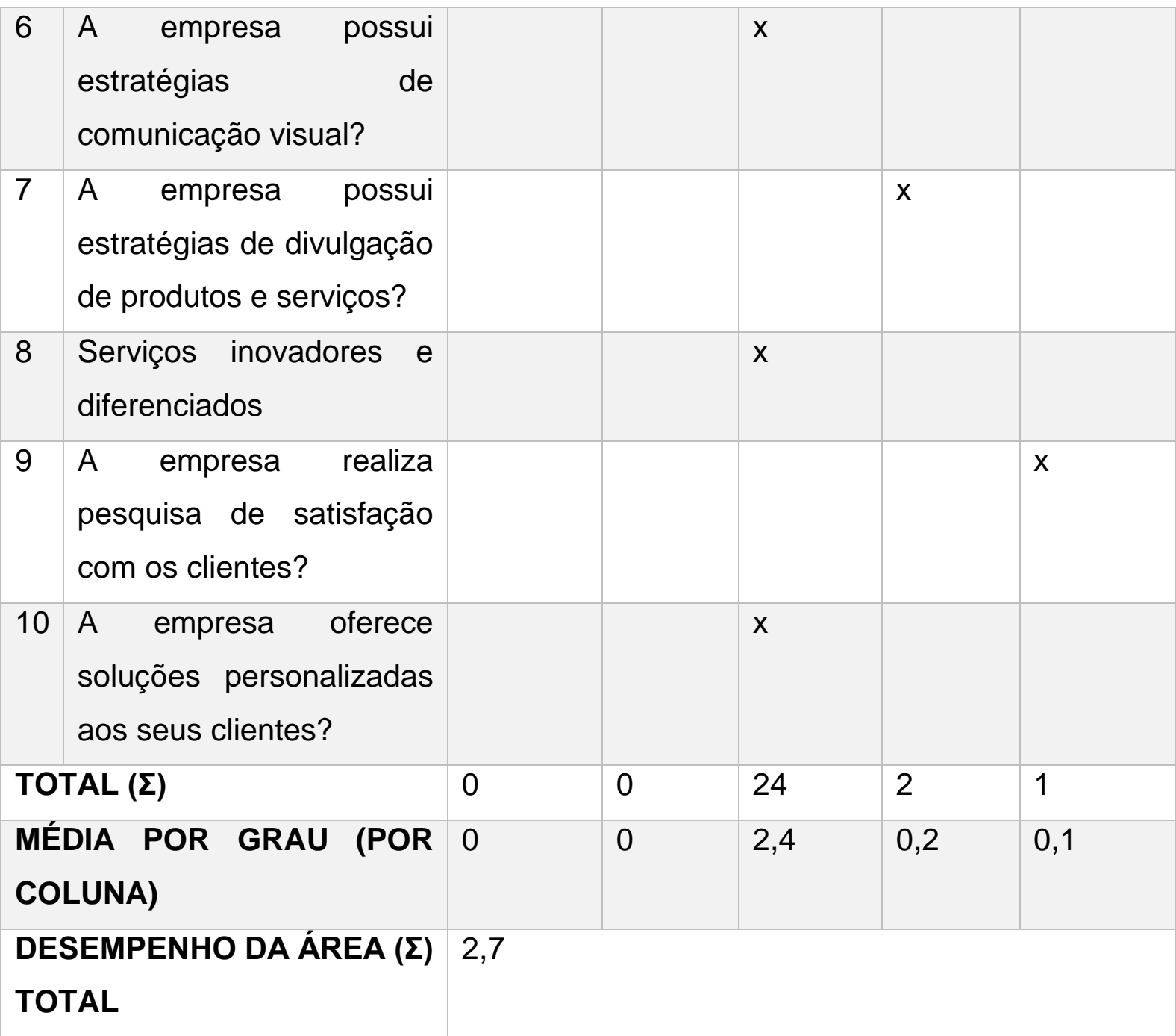

Fonte: Elaborado pelos autores do diagnóstico mediante pesquisa em campo, 2020.

Conforme apresentado no Quadro 01 acima, observam-se os principais fatores críticos considerados importantes, avaliados na área funcional Marketing da empresa Cross Nutrition. Onde o item 9) sobre pesquisa de satisfação com os clientes foi tido como o mais fraco, seguido do item 7) sobre as estratégias de divulgação de produtos e serviços. O item 8) Serviços inovadores e diferenciados como ponto médio, será utilizado dentre os demais citados para estudo de pesquisa e propostas de melhoria. Deste modo, a pergunta problema da pesquisa é: Como a implementação de uma 
estratégia combinada de ações de Marketing podem contribuir com a captação e fidelização dos clientes?

\subsection{PROPOSTA DE SOLUÇÃO}

A proposta de solução será em torno da área funcional Marketing, apontada como a área mais crítica avaliada. Onde será desenvolvido propostas de melhorias, afim de sanar o problema principal citado anteriormente.

O Marketing é indispensável para a longevidade de um empreendimento. Podendo alavancar seu negócio, se usado estrategicamente ferramentas digitais por exemplo ou fechar portas que poderiam ser oportunidades de crescimento. Com a globalização e a contínua mudança, cabe ao empreendedor se manter por dentro das tendências. Usando sabiamente as notícias e tecnologias a favor de sua empresa.

Elaborou-se um quadro de proposta de solução, com as respectivas ações listadas no Quadro 02 a seguir.

Quadro 02: Proposta de Solução

\begin{tabular}{|c|c|c|c|c|}
\hline Itens & Ações Interventivas & Cronologia & Duração & Custo \\
\hline 1 & $\begin{array}{l}\text { Desenvolver conteúdo } \\
\text { plataforma online de treinos }\end{array}$ & Abril/2021 & 2 meses & $\begin{array}{l}\mathrm{R} \$ \\
1.505,00\end{array}$ \\
\hline 2 & $\begin{array}{l}\text { Aquisição e Implantação da } \\
\text { plataforma digital }\end{array}$ & Junho/2021 & 1 dia & $\begin{array}{l}\mathrm{R} \$ 179,90 \\
\text { (Mensal) }\end{array}$ \\
\hline 3 & $\begin{array}{l}\text { Estruturar procedimentos } \\
\text { Marketing Digital }\end{array}$ & Abril/2021 & Mensal & $\mathrm{R} \$ 650,00$ \\
\hline
\end{tabular}

RC: 84713

Disponível em: https://www.nucleodoconhecimento.com.br/administracao/implementacaotecnologica 


\begin{tabular}{|l|l|l|l|l|}
\hline 4 & $\begin{array}{l}\text { Validar o uso do procedimento do } \\
\text { software CRM Hubspot }\end{array}$ & Março/2021 & 1 dia & $R \$ 650,00$ \\
\hline
\end{tabular}

Fonte: Elaborado pelos autores, fevereiro/2021.

Com isto as propostas de ações apresentadas no Quadro 02 acima, foram desenvolvidas visando captar e fidelizar seus clientes por meio de serviços inovadores no meio fitness manauara. Como a criação e o desenvolvimento de conteúdo do primeiro site de treinos Cross training personalizados do Brasil. Trabalhar a imagem da empresa Cross Nutrition Box Manaus, através das mídias sociais, criando uma conexão emocional com seus consumidores através das ferramentas do Marketing Digital. E por fim, a implantação e aquisição de um software CRM para coletar e organizar em um banco de dados as principais informações de seus clientes, para serem utilizadas na projeção de vendas da empresa.

Para organizar e planejar detalhadamente as ações, será utilizado a ferramenta $5 \mathrm{~W} 2 \mathrm{H}$. Que tem como objetivo estruturar o que é necessário e como será desenvolvido a meta específica por meio de perguntas chaves, como: O que fazer?; Por que será feito?; Onde será feito?; Quando fazer?; Quem fará?; Como fazer? E por último Quanto custará?.

A metodologia criada por esta ferramenta, utiliza tabelas para organizar o planejamento. Facilitando a visualização e o acompanhamento da ação pelos gestores, onde possibilita em tempo real a avaliação da efetividade da proposta. Podendo até mesmo ser adaptada se necessário, conforme mudanças dentro do tempo determinado inicialmente.

RC: 84713

Disponível em: https://www.nucleodoconhecimento.com.br/administracao/implementacaotecnologica 


\subsubsection{DESENVOLVER CONTEÚDO PARA PLATAFORMA ONLINE DE TREINOS}

Em decorrência do cenário atual de pandemia, o mundo fitness precisou se adaptar as novidades. Proporcionando as organizações à chance de se reinventarem, para se manterem competitivas independentemente das mudanças que possam vir a surgir também.

Com isto, a academia busca abranger o meio pelo qual transmite seus treinos: uma plataforma digital, com início do desenvolvimento para abril/2021. Visando atender o grupo-alvo que não pode ou opte por praticar em casa, seus alunos presenciais (Para que não haja cancelamento de matrículas, por falta de treinos), podendo captarem e atenderem alunos de todo o Brasil através da facilidade que a internet permite.

Quadro 03: 5W2H - Desenvolver conteúdo para uma plataforma online de treinos

\section{Desenvolver conteúdo para uma plataforma online de treinos}

O que? Criação de conteúdo para a plataforma de vendas de produtos digitais, ofertando vídeos de treinos exclusivos de Cross Training.

Por quê? Para atender ao público que não possa ou opte por não sair de casa para treinar, dando a alternativa online. Além de ser um potencial acelerador para captar clientes, em virtude que o site pode abranger seu público a outras cidades.

Onde? Na própria empresa

Quando? Abril 2021

Quem? Empresa terceirizada

Como? Contratar um profissional apto para edição das aulas em formato de vídeo, que serão disponíveis pela empresa através da plataforma.

Quanto? R $\$ 1.505,00$

Fonte: Elaborado pelos autores, 2021.

RC: 84713

Disponível em: https://www.nucleodoconhecimento.com.br/administracao/implementacaotecnologica 
O Quadro 03 acima, apresenta o planejamento para o desenvolvimento e criação do conteúdo da plataforma digital de treinos. Onde nesta primeira etapa, será definido e gravada as aulas/treinos e a contratação temporária para edição das aulas em formato de vídeo de um editor profissional para alimentar o site com estes produtos digitais. As aulas gravadas serão filmadas nas locações da academia Cross Nutrition Box Manaus, e terá duração de 2 meses de gravação e edição do conteúdo com início em Abril/2021 e término no final de Maio/2021.

\subsubsection{AQUISIÇÃO $\quad$ E IMPLANTAÇÃO DA PLATAFORMA ONLINE PARA TREINOS}

A aquisição e implantação da plataforma tem como previsão de lançamento para o $1^{\circ}$ semestre de 2021 , em Junho. Onde o projeto desenvolvido entrará em ação, com a finalidade de captar e reter alunos com um serviço/ produto digital inovador no segmento fitness. Propiciando um novo método de transmissão do treino funcional Cross training e estilo militar.

A plataforma digital surge como um potencial acelerador para o crescimento da academia Cross Nutrition, sendo um diferencial competitivo no meio fitness manauara.

Quadro 04: 5W2H - Aquisição e Implantação da plataforma online para treinos

\section{Aquisição e Implantação da plataforma online para treinos}

O que? Aquisição e Implantação da plataforma de vendas de produtos digitais criada em abril/2021 através de um sistema de gestão, com taxa mensal de funcionamento do sistema inserido na empresa.

Por quê? Como a academia possui mais de 100 alunos e ultrapassa o pacote grátis do sistema, entra no plano da empresa desenvolvedora da plataforma com esta taxa mensal de gerenciamento.

RC: 84713

Disponível em: https://www.nucleodoconhecimento.com.br/administracao/implementacao$\underline{\text { tecnologica }}$ 


\begin{tabular}{|l|l|}
\hline Onde? & Na própria empresa \\
\hline Quando? & Junho/2021 \\
\hline Quem? & Empresa terceirizada \\
\hline Como? & $\begin{array}{l}\text { Contratar uma empresa terceirizada especialista para a criação e o } \\
\text { gerenciamento da plataforma digital. }\end{array}$ \\
\hline Quanto? & $\mathrm{R} \$ 179,90$ (taxa mensal) \\
\hline
\end{tabular}

Fonte: Elaborado pelos autores, 2021.

No Quadro 04 acima, é a fase final e aplicação da primeira fase do plano de ação: plataforma digital. Neste quadro apresenta a aquisição e implantação do sistema de gestão pelo qual será colocado em prática a ideia do site, este sistema disponibiliza a estrutura pronta para a criação, domínio (nome do site escolhido pelo usuário) de uma plataforma de vendas, aplicativo e o gerenciamento da organização via online. Para usufruir do sistema, é necessário embolsar mensalmente uma taxa para a disponibilização dos benefícios ofertados acima, no caso do quantitativo de alunos na academia Cross Nutrition é indicado a taxa de $\mathrm{R} \$ 179,90$ para atender até 300 alunos online, não limitando ao atendimento de alunos em forma presencial. Posteriormente podendo ser alterado o plano escolhido, caso tenha um acréscimo nesse quantitativo. Sua implantação na organização está prevista para Junho/2021, sem previsão de término.

\subsubsection{ESTRUTURAR PROCEDIMENTOS DE MARKETING DIGITAL}

O Marketing digital será utilizado na pesquisa como a principal ferramenta de atração e fidelização de clientes, por intermédio dele é possível atingir um número amplo e expressivo de usuários que se identificarão e terão o interesse em fazer parte da organização, virtualmente através das mídias sociais ativas como Instagram, Facebook, Twitter, Sites e E-mail. Sendo esses os principais meios de comunicação oferecidos pela empresa, afim de fornecer o melhor atendimento para os clientes.

RC: 84713

Disponível em: https://www.nucleodoconhecimento.com.br/administracao/implementacaotecnologica 
Quadro 05: 5W2H - Estruturar procedimentos de Marketing Digital

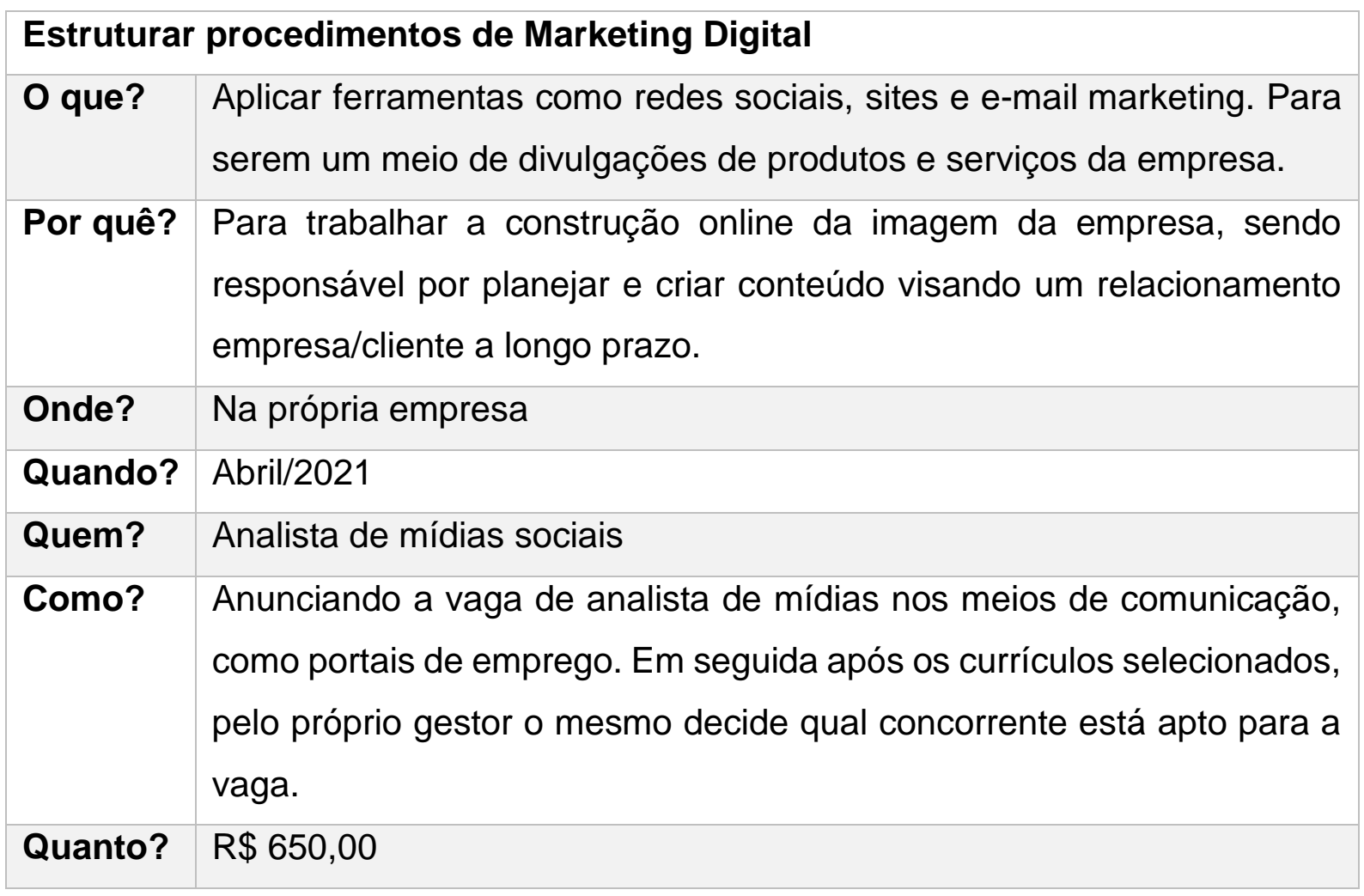

Fonte: Elaborado pelos autores, 2021.

O Quadro 05 acima, ressalta com detalhes o planejamento da estruturação do marketing digital. Seu principal objetivo é auxiliar na construção da identidade da marca de forma online, tornando-se responsável por organizar e gerar conteúdos, visando proporcionar uma relação direta da empresa com seus clientes a um longo período. O plano deve ser implantado na própria empresa, através da colaboração de um profissional de análise de mídias sociais, para assim alcançar o público-alvo da organização de maneira orgânica. Com início previsto para Abril/2021, sem data para o término. $O$ custo foi estabelecido pelos autores tendo em base o valor de mercado. 


\section{$\begin{array}{llllll}\text { 4.1.4 VALIDAR } & 0 & \text { USO DO } & \text { PROCEDIMENTO DO }\end{array}$ SOFTWARE CRM HUBSPOT}

Atualmente é possível encontrar software CRM gratuito, podendo ser cobrado uma taxa mensal caso exceda o limite de dados cadastrais oferecido pelo pacote gratuito do software ou a empresa opte pelo pacote premium.

Para a Cross Box Nutrition Manaus o software escolhido foi o Hubspot, onde atuará alimentando o sistema com os dados cadastrais dos consumidores, armazenando todas as ações de compras, identificando clientes em potencial, obtendo informações referente aos gostos e desejos dos clientes e leads, mantendo dados constantemente atualizados e capacitando o alcance de novos consumidores. Tendo em conta vendas futuras e priorizando as melhores oportunidades, ofertando produtos e serviços específicos mais procurados na plataforma e academia presencial, através da filtragem de informações que o CRM disponibiliza à empresa.

Quadro 06: 5W2H - Validar o uso do procedimento do software CRM Hubspot

\section{Validar o uso do procedimento do software CRM Hubspot}

O que? Instalar um software de CRM que obtenha dados de cadastros dos clientes, que registre as opções de compras dos consumidores, que mantenha os dados atualizados e estabeleça comunicação com os mesmos.

Por quê? Para ter mais informações do cliente e seus gostos afim de ampliar o seu cadastro e ampliar as vendas da academia. O software gratuito atende os mesmos requisitos que as versões pagas oferecem e a empresa necessita.

Onde? Empresa terceirizada

Quando? Março/2021

Quem? Analista de mídias sociais, especializado em software CRM.

RC: 84713

Disponível em: https://www.nucleodoconhecimento.com.br/administracao/implementacaotecnologica 
Como? Instalando um software gratuito de CRM para uso imediato do Analista de mídias sociais e o gestor. Sendo assim o analista responsável também pelas redes sociais, consegue ter precisão no que o público necessita criando estratégias para captar e fidelizar os clientes por meio do software.

\section{Quanto? R $\$ 650,00$}

Fonte: Elaborado pelos autores, 2021.

O Quadro 06 acima, destaca a implantação do software Hubspot a ser instalado na empresa com intuito de registrar dados cadastrais de seus clientes, a ferramenta é oferecida gratuitamente pela empresa terceirizada citada anteriormente. Ele será o meio fundamental para a precisão da necessidade do público da organização e terá uma visão clara tanto das redes sociais da empresa quanto das informações cadastradas no CRM, ambos gerenciados pelo Analista de mídias sociais especializado no software em conjunto a supervisão do gestor da organização. O mês de início proposto será em Março/2021, sem data de término previsto.

\section{CONSIDERAÇÕES FINAIS}

No mercado atual globalizado, com constantes mudanças nos negócios e expectativas cada vez mais altas dos clientes, cabe as organizações se manterem antenadas ao que o cenário exige, para que obtenham um diferencial competitivo e permaneçam sólidas no mercado. Para isto é necessário o comprometimento de todos os colaboradores da empresa, afim de que os objetivos estratégicos sejam alcançados da melhor maneira. Nesta sequência, o presente trabalho primeiramente mapeou os processos mediante Diagnóstico Organizacional desenvolvido na empresa.

$\mathrm{Na}$ etapa citada pôde-se avaliar alguns aspectos da empresa como o segmento de mercado, o público-alvo da academia, seu porte, missão, visão, valores, metas e os

RC: 84713

Disponível em: https://www.nucleodoconhecimento.com.br/administracao/implementacaotecnologica 
objetivos da organização, complementarmente foi analisado as áreas funcionais da academia por meio de questionários, observação direta, reuniões com o gestor e entrevista com seus colaboradores. Com isto a área do Marketing foi avaliado como a mais crítica da organização, já que a pesquisa de satisfação com os clientes foi baixo e a empresa não possui estratégias de divulgação dos seus produtos/serviços e não desenvolvem ideias para inovar nos serviços oferecidos.

Na segunda etapa foi realizado a Proposta de Solução com o objetivo de encontrar as soluções mais viáveis a cultura organizacional e à capacidade da empresa, com o intuito de aperfeiçoar os gargalos na academia Cross Nutrition Box Manaus. Foi desenvolvido por meio de análise dos recursos e materiais, dos custos, do perfil do público-alvo e das inovações na prestação de serviços, para dessa maneira propor a solução mais adequada a realidade as empresa.

Com base no desenvolvido na segunda etapa indica-se uma grande possibilidade da empresa resolver seus obstáculos e começar um processo de melhoria contínua no relacionamento, fidelização de clientes e implantação de um novo meio de transmissão de seus treinos. Com o uso de softwares e ferramentas do marketing digital se bem gerenciados e executados, a organização tende a obter ganhos significativos tanto no fator econômico quanto na longevidade do relacionamento com seus clientes, gerando assim valor para ambas as partes.

\section{REFERÊNCIAS BIBLIOGRÁFICAS}

BAPTISTA, José Ricardo. Relacionamento com clientes. 1 ed. Curitiba, PR: IESDE BRASIL S/A,2016.

BERTÃO, Naiara. A nova era do mercado fitness: academias apostam em serviços on-line e dinheiro por indicações. Valor Investe, 2020. Disponível em: $\quad<h t t p s: / / v a l o r i n v e s t e . g l o b o . c o m / o b j e t i v o / e m p r e e n d a-s e / n o t i c i a / 2020 / 04 / 30 / a-$ 
nova-era-do-mercado-fitness-academias-apostam-em-servicos-on-line-e-dinheiropor-indicacoes.ghtml>. Acesso em: 20 fev. 2021.

CARVALHO, Luis Osete Ribeiro et al. Metodologia científica: teoria e aplicação na educação a distância. Petrolina, 2019.

Comece a crescer hoje mesmo com as ferramentas gratuitas do Hubspot. Hubspot, 2016. Disponível em: <https://br.hubspot.com/pricing/crm>. Acesso em: 20 de fev. 2021.

CUSTÓDIO, Marcos Franqui. Gestão da qualidade e produtividade. São Paulo: Pearson Education do Brasil, 2015.

DONNELLY JR., James H.; PETER, J. Paul. Introdução ao marketing: criando valor para clientes. 1. ed. São Paulo: Saraiva, 2013.

KOTLER, P.; KARTAJAYA, H.; SETIAWAN, I. Marketing 4.0: Mudança do Tradicional para o Digital. Lisboa: Actual, 2017.

KUENDEE, Punyisa. Application of 7 quality control (7 QC) tools for quality management: A case study of a liquid chemical warehousing. 4th International Conference on Industrial Engineering and Applications (ICIEA): Nagoya, 2017, p.106110.

LIBÓRIO, Daisy; TERRA, Lucimara. Metodologia científica. São Paulo: Rede Internacional de Universidades Laureate, 2015.

Qual é o Mobitrainer certo para sua academia?. Mobitrainer, 2019. Disponível em: <https://mobitrainer.com.br/planos_e_precos/academia>. Acesso em: 20 de fev. 2021.

MARANGONI, Suzana. Marketing de serviços. Rio de Janeiro: SESES,2015.

RC: 84713

Disponível em: https://www.nucleodoconhecimento.com.br/administracao/implementacaotecnologica 
RAIOL, Rodolfo de Azevedo. Estratégias para aumentar captação, retenção e diminuir a evasão de Clientes em Academias. Vol.10. Revista Intercontinental de Gestão Desportiva, 2020.

RODRIGUES LEITE, H. C. Ferramentas da qualidade: um estudo de caso em empresa do ramo têxtil. 2013. 53 f. Monografia (Graduação em Administração) Faculdade Cenecista de Capivari, Capivari, 2013.

SILVA, Lúcia Aparecida da. Administração de marketing. Rio de Janeiro: SESES, 2015.

SOUTO, Rodrigo. Automação de marketing. Hubspot, 2020. Disponível em: <https://br.hubspot.com/blog/marketing/automacao-de-marketing>. Acesso em: 20 fev. 2021.

VERAS, Manoel. Gestão dinâmica de projeto. Rio de Janeiro: Brasport, 2016.

VERGARA, Sylvia Constant. Projetos e relatórios de pesquisa em administração. 16. ed. São Paulo: Atlas, 2016.

ZANELLA, Liane Carly Hermes. Metodologia de pesquisa. 2. ed. Reimp. Florianópolis: Departamento de Ciências da Administração/ UFSC, 2013.

Enviado: Março, 2021.

Aprovado: Maio, 2021.

RC: 84713

Disponível em: https://www.nucleodoconhecimento.com.br/administracao/implementacaotecnologica 